\title{
Comparative Transcriptome Analysis Reveals a Preformed Defense System in Apple Root of a Resistant Genotype of G.935 in the Absence of Pathogen
}

\author{
Yanmin Zhu, ${ }^{1}$ Jonathan Shao, ${ }^{2}$ Zhe Zhou, ${ }^{3}$ and Robert E. Davis ${ }^{2}$ \\ ${ }^{1}$ USDA-ARS, Tree Fruit Research Laboratory, Wenatchee, WA 98801, USA \\ ${ }^{2}$ USDA-ARS, Molecular Plant Pathology Laboratory, Beltsville, MD 20705, USA \\ ${ }^{3}$ Tree Fruit Research Institute, Chinese Academy of Agricultural Sciences, Xingcheng, Liaoning 10081, China \\ Correspondence should be addressed to Yanmin Zhu; yanmin.zhu@ars.usda.gov
}

Received 14 October 2016; Revised 9 February 2017; Accepted 1 March 2017; Published 30 March 2017

Academic Editor: Anca Macovei

Copyright (C) 2017 Yanmin Zhu et al. This is an open access article distributed under the Creative Commons Attribution License, which permits unrestricted use, distribution, and reproduction in any medium, provided the original work is properly cited.

\begin{abstract}
Two apple rootstock genotypes G.935 and B.9 were recently demonstrated to exhibit distinct resistance responses following infection by Pythium ultimum. As part of an effort to elucidate the genetic regulation of apple root resistance to soilborne pathogens, preinoculation transcriptome variations in roots of these two apple rootstock genotypes are hypothesized to contribute to the observed disease resistance phenotypes. Results from current comparative transcriptome analysis demonstrated elevated transcript abundance for many genes which function in a system-wide defense response in the root tissue of the resistant genotype of G.935 in comparison with susceptible B.9. Based on the functional annotation, these differentially expressed genes encode proteins that function in several tiers of defense responses, such as pattern recognition receptors for pathogen detection and subsequent signal transduction, defense hormone biosynthesis and signaling, transcription factors with known roles in defense activation, enzymes of secondary metabolism, and various classes of resistance proteins. The data set suggested a more poised status, which is ready to defend pathogen infection, in the root tissues of resistant genotype of G.935, compared to the susceptible B.9. The significance of preformed defense in the absence of a pathogen toward overall resistance phenotypes in apple root and the potential fitness cost due to the overactivated defense system were discussed.
\end{abstract}

\section{Introduction}

During their coevolution with pathogens, plants developed a sophisticated, two-layered innate immune system that confers resistance against most microbial pathogens [1-3]. The first line of defense is initiated upon perception of a conserved pathogen-associated molecular pattern (PAMP) by pattern recognition receptor ( $\mathrm{PRR}$ ) embedded in the plant's plasma membrane, activating so-called PAMP-triggered immunity (PTI). PTI is generally considered as a basal, nonspecific response [1]. However, adapted pathogens are able to counteract the basal resistance of a host through the secretion of evolved molecules called "effector" proteins, which suppress or bypass PTI [4-6]. On the plant side, coevolved resistance (R) genes directly or indirectly detect pathogen virulence effectors and initiate the second layer of defense called effector-triggered immunity (ETI) $[1,7]$. The second layer of plant immunity relies on the specific recognition of pathogen effectors by disease resistance proteins (R), leading to a strong and specific immune response toward those isolates of a pathogen that produce the recognized effector. These common responses of plant defense systems occur after the plant encounters a pathogen, but is it possible that in some cases plant defenses are already "primed" before inoculation?

The genus Pythium, which consists of over 100 species, is ubiquitously distributed and capable of long-term survival in soil by producing thick-walled oospores. Germination of phytopathogenic Pythium spp. oospores initiates infections of seeds or roots [8]. P. ultimum is one of its most significant plant pathogens from this genus and infection by this pathogen results in damping off or root rot, which leads 
to plant wilting, reduced yield, and mortality on many economically important crops [9]. P. ultimum is also identified as a major component in the pathogen complex which incited apple replant disease [10]. A recent study using two apple rootstock genotypes demonstrated that G.935 is more resistant, and B.9 is more susceptible, to infection by $P$. ultimum [11]. In the present study, as part of an effort to elucidate the genetic regulation of apple root resistance to soilborne pathogens, it was hypothesized that preinoculation transcriptome variation(s) in roots contributes to genotypespecific disease resistance.

To test this hypothesis, a comparison of global transcriptional landscape in the root tissues of two apple rootstock cultivars (B.9 and G.935) before inoculation was carried out using RNA-seq based transcriptome sequencing; the two cultivars were recently demonstrated to exhibit distinct resistance responses following infection by P. ultimum [11]. The results of our study revealed that the defense system of the more highly disease resistant apple rootstock genotype G.935 was poised at an elevated level prior to intentional inoculation with a pathogen. The finding is reminiscent of the recent report of so-called preformed defense or the elevated and constitutive expression of plant defense genes contributing to genotype-specific disease resistance among rice genotypes [12]. The present observations and those of others $[12,13]$ raise questions concerning the mechanisms that are responsible for elevation of defense systems before inoculation.

\section{Materials and Methods}

2.1. Preparation by Tissue Culture Procedure and Maintenance of Plant Materials. Tissue culture based micropropagation procedures were used to obtain cloned plants for both apple rootstock genotypes as described previously [11]. To minimize the influence of nongenetic factors, a synchronized micropropagation procedure was employed to generate plants of equivalent developmental stage for both B.9 and G.935. Specifically, the root tissues of 4-week-old plants after root induction in tissue culture medium were then transferred to pasteurized (in an oven at $85^{\circ} \mathrm{C}$ for two consecutive overnights) Sunshine ${ }^{\mathrm{TM}}$ potting mix soil (SUN GRO Horticulture Ltd, Bellevue, WA) for a period of one week with "in-soil" acclimation in a growth chamber to further the differentiation of root tissues. To minimize transplanting effects from tissue culture medium to soil condition, a transparent $7^{\prime \prime}$ Vented Humidity Dome (Greenhouse Megastore, Danville, IL) was placed on top of a $10 \times 20$-inch flat tray holding the pots for retention of humidity. Root tissues were collected by flash freezing in liquid nitrogen and stored at $-80^{\circ} \mathrm{C}$ before RNA isolation.

\subsection{Total RNA Isolation and High-Throughput mRNA Sequen-} cing. Total RNA isolation followed the method previously described in Zhu et al., 2016 [11]. Root tissues of both resistant G.935 and susceptible B.9 were represented by three biological replicates, and each replicate included the pooled root tissues from three plants. The frozen root tissue samples were ground to a fine powder in liquid nitrogen, and RNA quantity was determined using a Nanodrop spectrophotometer (ND1000; Thermo Fisher Scientific). The RNA integrity number (RIN) was evaluated using an Agilent 2100 Bioanalyzer. Only RNA with an RIN value of $x \geq 8$ was used for RNA-seq. Oligo (dT) magnetic beads were utilized to isolate poly-(A) tails containing mRNAs from total RNA and then fragmentation buffer was added to interrupt mRNA to short fragments. Using these short fragments as templates, first-strand cDNA was synthesized using reverse transcriptase and a random hexamer primer. Second-strand cDNA fragments were then synthesized using a buffer, DNA polymerase I, dNTPs, and RNase $H$. After purification and paired-end $(\mathrm{PE})$ repair protocols were performed, the cDNA fragments were ligated to sequencing adapters and amplified using PCR to obtain the final PE cDNA library. The library preparation and RNAsequencing with $150 \mathrm{bp}$ paired-end (PE) were completed at the Center for Genome Research and Biocomputing in Oregon State University using an Illumina HiSeqTM 3000 (Illumina Inc., San Diego, CA, USA).

2.3. Mapping of Sequence Reads and Differentially Expressed Gene Analysis. Reads from B.9 (susceptible) and G.935 (resistant) libraries were mapped to the nucleotide sequences of predicted coding genes of the Malus $\mathrm{x}$ domestica Whole Genome v3.0.al (https://www.rosaceae.org/analysis/162) using the ultrafast, memory-efficient short read aligner Bowtie 2-2.2.5 which utilizes a Burrows-Wheeler index [14]. Count data were obtained for each coding sequence. Estimation and statistical analysis of expression levels using count data of each gene with 3 replicates for each library was performed using the DEseq2 package [15] and R x64 3.3.1 program (https://www.r-project.org/). Differentially expressed genes (DEGs) were identified by comparing transcript abundance between B.9 and G.935 root transcriptome data set with the cutoff values of $\log _{2}$ fold change $\geq 2$; and + indicated higher transcript level in the root of G.935 over that in B.9; - indicated the opposite. The annotation of these genes was carried out by BLASTP [13] against NR (nonredundant protein sequences) database and a BLAST database containing genomic sequences for Arabidopsis (Arabidopsis thaliana), corn (Zea mays), Medicago truncatula, rice (Oryza sativa), and tomato (Solanum lycopersicum).

\subsection{Validation of the Expression Pattern of Identified DEGs} by $q R T-P C R$. The same total RNAs that were used for RNAseq experiments were also used for RNA-seq data validation by qRT-PCR. The total RNA was treated with DNase I (Qiagen, Valencia, CA) and then purified with RNeasy cleanup columns (Qiagen, Valencia, CA). Two $\mu$ g of DNasetreated RNA was used to synthesize first-strand cDNA using SuperScript ${ }^{\mathrm{TM}}$ II reverse transcriptase (Invitrogen, Grand Island, NY) and poly dT (Operon, Huntsville, AL) as the primer. The cDNA was diluted 20 times and $0.6 \mu \mathrm{L}$ aliquot was used in a $15 \mu \mathrm{L}$ quantitative PCR (qPCR) reaction mix: $0.45 \mu \mathrm{L}$ SYBR Green I dye (Invitrogen, Grand Island, NY), 1x iTaq buffer (Biorad, Hercules, CA), $0.2 \mathrm{mM}$ dNTP (Applied Biosystems, Waltham, MA), $2.5 \mathrm{mM} \mathrm{MgCl}, 0.3$ units of iTaq 
TABLE 1: Illumina reads and alignment to apple gene models.

\begin{tabular}{lcc}
\hline Biological replicates & Number of fastq sequences & Overall alignment rate (percentage) \\
\hline B.9-1.fastq & 28327388 & 44.61 \\
B.9-2.fastq & 33356252 & 49.23 \\
B.9-3.fastq & 25790809 & 52.76 \\
\hline G.935-1.fastq & 26469741 & 47.64 \\
G.935-2.fastq & 18354709 & 51.71 \\
G.935-3.fastq & 23359343 & 46.89 \\
\hline
\end{tabular}

DNA polymerase (Biorad, Hercules, CA), and $0.2 \mu \mathrm{M}$ forward/reverse primer (IDT, Coralville, IA). Real-time qPCR amplification and detection was conducted using an iQ5 realtime qPCR detection system (Biorad Lab, Hercules, CA) and the following protocol: cycle conditions of $3 \mathrm{~min}$ at $95^{\circ} \mathrm{C}$ and 40 cycles of $10 \mathrm{~s}$ at $95^{\circ} \mathrm{C}$ and $30 \mathrm{~s}$ at $59^{\circ} \mathrm{C}$. Dissociation curves were run for all of the primers used in this study to determine the presence of any nonspecific amplification. The relative gene expression was measured using the lowest $\mathrm{Ct}$ value as the calibrator. "No reverse transcriptase" and "no template" negative controls were included in PCR amplification. Each sample was represented by two independent total RNA isolations converted into two separate cDNAs. Each cDNA sample included two replicates for PCR reactions. Therefore, four separate PCR amplifications (four replicates) were performed on each sample. PCR amplification was carried out in triplicate in a 96-well plate. The target gene expression was normalized to that of the internal reference gene (MdActin) using the $2^{-\Delta \Delta C T}$ method (the comparative Ct method) [16].

\section{Results}

3.1. Statistic of Read Mapping and DEG Identification. The numbers of raw reads by RNA-seq and alignment rate for three biological replicates from both B.9 and G.935 genotypes were shown in Table 1. Approximately two-thirds of the predicted CDs (Malus_x_domestica.v3 .0.al_gene_set_cds.fasta.gz) were shown to have reads that mapped. $\log _{2}$ FC values of 2 and greater were used as the criteria for differentially expressed gene (DEG) identification, and about $3.01 \%$ of all predicted genes in apple genome were identified as DEGs between these two genotypes. Upregulation denotes the higher transcript level in the roots of G.935; conversely, downregulation indicates the lower transcript level in G.935 compared that in B.9. The functional annotation for these DEGs were assigned based on the searching the NR database and the Arabidopsis, tomato, corn, rice, poplar, and Medicago protein sequences in GenBank.

3.2. DEGs with Annotated Function of Defense Hormone Biosynthesis and Signaling. Previously, two apple rootstock cultivars, B.9 and G.935, have demonstrated distinct resistance response to Pythium ultimum [11] and Rhizoctonia solani (Zhu, unpublished data). Ethylene and jasmonic acid (JA) are well known to be the defense hormones in combating necrotrophic pathogens $[17,18]$. As shown in Table 2, in the root tissues without exposure to the pathogen, several DEGs with annotated functions of ethylene biosynthesis and signaling were identified. Two "1-aminocyclopropane-1carboxylate synthase" (ACS) encoding genes and three "1aminocyclopropane-1-carboxylate oxidase” (ACO) encoding genes showed considerable higher level of detected transcripts in G.935 than in B.9. Two of three "lipoxygenase" encoding genes, which function in JA biosynthesis pathway, also showed more abundant transcripts in G.935 than in B.9 root tissue. Three out of five genes encoding ERFs (ethylene response factors), which play roles in integrating ET/JA signals, were shown to be with higher expression level in the roots of G.935 as compared with those of B.9. DEGs for gibberellin (GA) signaling and biosynthesis appear to be differentially expressed in the root tissues of two cultivars. There were three receptor GID1 encoding genes showing higher transcript level in G.935 roots compared to that in B.9. On the other hand, two DEGs encoding "gibberellin 2-betadioxygenase," which is involved in GA biosynthesis, were either up- or downregulated. The higher transcript levels for both "abscisic acid $8^{\prime}$-hydroxylase" encoding genes, which involve abscisic acid (ABA) metabolism, were detected in the roots of G.935. Overall, the elevated transcriptional activities related to defense hormone metabolism and signaling were shown to exist in the root tissue of the more resistant genotype of G.935 than in the roots of the susceptible apple rootstock genotype of B.9.

3.3. DEGs with Annotated Function of Pattern Recognition Receptors (PRRs) or Receptor with Defense Implication. DEGs encoding several categories of plant PRRs were identified based on root transcriptome comparison between two apple rootstock genotypes (Table 3; Supplementary File number 1 in Supplementary Material available online at https://doi.org/10.1155/2017/8950746). LysM domain receptors are known to be able to bind PAMPs such as chitin from fungal pathogens $[19,20]$ and detect the presence of pathogens. The higher transcript levels of four LysM domain receptors encoding genes were detected in the roots of G.935 as compared to those from B.9. Two DEGs encoding "BRASSINOSTEROID INSENSITIVE1-associated receptor kinase 1-like receptors" showed significantly higher level of detected transcripts in G.935 than in B.9. A total of 15 WAK (wall associated kinase) or WAK-like encoding genes were shown to be differentially expressed between the root tissues from two cultivars, although 9 out of 15 of them exhibited 
TABLE 2: DEGs with annotated function in defense hormone biosynthesis and signaling.

\begin{tabular}{|c|c|c|}
\hline Apple gene model $^{\mathrm{a}}$ & Functional annotations $^{\mathrm{b}}$ & $\log _{2} \mathrm{FC}^{\mathrm{c}}$ \\
\hline \multicolumn{3}{|c|}{ Ethylene (ET) biosynthesis } \\
\hline MDP0000286210 & ACS 7-like & +2.0 \\
\hline MDP0000413933 & ACS 8-like & +2.1 \\
\hline MDP0000282901 & ACO 4-like & +2.1 \\
\hline MDP0000593536 & ACO homolog & +2.1 \\
\hline MDP0000473933 & ACO 1-like & +2.9 \\
\hline \multicolumn{3}{|c|}{ Jasmonic acid (JA) biosynthesis } \\
\hline MDP0000281525 & Linoleate 13S-lipoxygenase 2-1 & +3.0 \\
\hline MDP0000753547 & Linoleate 13S-lipoxygenase $2-1$ & +2.4 \\
\hline MDP0000154928 & Lipoxygenase & -2.5 \\
\hline \multicolumn{3}{|l|}{ ET/JA signaling } \\
\hline MDP0000297771 & ERF 4 & +4.0 \\
\hline MDP0000262710 & ERF 027-like & +2.8 \\
\hline MDP0000128326 & ERF RAP2-11-like & +2.4 \\
\hline MDP0000246808 & ERF 1B-like & -2.1 \\
\hline MDP0000447570 & ERF 1B-like & -2.2 \\
\hline MDP0000825712 & Topless-related protein 4-like & +2.6 \\
\hline MDP0000313085 & Topless-related protein 1-like isoforms X3 & -2.2 \\
\hline \multicolumn{3}{|c|}{ Gibberellin (GA) biosynthesis and signaling } \\
\hline MDP0000769340 & GA receptor GID1 & +5.2 \\
\hline MDP0000682570 & GA receptor GID1 & +3.6 \\
\hline MDP0000161639 & GA receptor GID 1C-like & +2.3 \\
\hline MDP0000431628 & DELLA protein RGL1-like & +2.5 \\
\hline MDP0000126248 & GA 2-beta-dioxygenase 7-like & +2.4 \\
\hline MDP0000226405 & GA 2-beta-dioxygenase 2-like & -2.1 \\
\hline \multicolumn{3}{|c|}{ Abscisic acid biosynthesis } \\
\hline MDP0000300259 & ABA $8^{\prime}$-hydroxylase 3-like & +2.1 \\
\hline MDP0000326412 & ABA $8^{\prime}$-hydroxylase 2 & +3.7 \\
\hline \multicolumn{3}{|l|}{ Cytokinin biosynthesis } \\
\hline MDP0000318353 & Cytokinin dehydrogenase 1-like & +2.6 \\
\hline
\end{tabular}

lower transcript levels in G.935. Notably, more than half of these DEGs encode WAK-like 16 homologs.

3.4. Lectin Receptor Kinase, Glutamate Receptor Encoding Genes, and Other Receptor Kinases. Lectin-domain containing receptor kinases are known to participate in immune response and resistance signal transduction in other pathosystems [21, 22]. Between the root tissues for two apple rootstock cultivars, ten "L-type lectin-domain containing receptor kinase" and 25 "G-type lectin S-receptorlike serine/threonine-protein kinase" encoding genes showed differential expression patterns (Table 4). Most of these receptor kinase-encoding genes exhibited higher transcript abundance in the resistant cultivars G.935. Fourteen "glutamate receptor" encoding genes were identified as DEGs between two cultivars; and most (9 out of 14) of them showed the elevated expression levels in the roots of G.935 as compared to B.9. The biological function of glutamate receptor is not well understood, but preliminary data point to its roles in defense response [23, 24]. Additionally, there were many DEGs which were annotated as LRR receptor-like serine/threonine-protein kinase, receptor-like protein kinase, receptor-like protein, and cysteine-rich receptor-like protein kinase. Double or triple the numbers of DEGs showed higher transcript levels in the root tissues of G.935, in contrast to relatively small number of genes with the lower transcript levels (Table 5; Supplementary File number 1).

3.5. DEGs with the Annotated Function of Oxidation and Reduction Processes. The balance of ROS production for the purpose of defense signaling and the scavenging capacity to avoid cellular damage could be critical in plant immunity 
TABLE 3: DEGs encoding proteins with annotated function of pattern recognize receptor (PRR).

\begin{tabular}{|c|c|c|}
\hline Apple gene model ${ }^{\mathrm{a}}$ & Functional annotations $^{\mathrm{b}}$ & $\log _{2} \mathrm{FC}^{\mathrm{c}}$ \\
\hline \multicolumn{3}{|c|}{ Chitin elicitor receptor kinase 1- (CERK1-) like receptor } \\
\hline MDP0000182108 & lysM domain receptor-like kinase 3 & +3.13 \\
\hline MDP0000137744 & lysM domain receptor-like kinase 3 & +2.76 \\
\hline MDP0000225637 & lysM domain receptor-like kinase 4 & +3.10 \\
\hline MDP0000172006 & lysM domain receptor-like kinase 4, isoform X1 & +2.0 \\
\hline \multicolumn{3}{|c|}{ BRASSINOSTEROID INSENSITIVE1-associated receptor kinase 1-like receptor } \\
\hline MDP0000651862 & BAK1 & +6.2 \\
\hline MDP0000423334 & BAK1 & +5.5 \\
\hline \multicolumn{3}{|c|}{ Wall associated kinase- (WAK-) like receptor } \\
\hline MDP0000278145 & WAK-like protein & -5.63 \\
\hline MDP0000311732 & WAK-like protein & -2.45 \\
\hline MDP0000281090 & Putative WAK-like 16 & -2.60 \\
\hline MDP0000426154 & Putative WAK-like 16 & -2.67 \\
\hline MDP0000656197 & Putative WAK-like 16 & -3.02 \\
\hline MDP0000169245 & Putative WAK-like 16 & -2.40 \\
\hline MDP0000281090 & Putative WAK-like 16 & -3.0 \\
\hline MDP0000837936 & Putative WAK-like 16 & -2.05 \\
\hline MDP0000354964 & Putative WAK-like 16 & +4.12 \\
\hline MDP0000276990 & Putative WAK-like 16 & +2.31 \\
\hline MDP0000167101 & WAK4-like & -2.14 \\
\hline MDP0000465085 & WAK3-like & +2.04 \\
\hline MDP0000170906 & WAK2-like & +2.10 \\
\hline MDP0000354964 & WAK2-like & +4.12 \\
\hline MDP0000153539 & WAK-like 8 isoform X2 & +2.8 \\
\hline
\end{tabular}

[25]. A total of 27 DEGs encoding proteins involved with the oxidation and reduction process were identified from transcriptome comparison between these two cultivars, including "glutathione S-transferase," "peroxidase," and "superoxide dismutase" (Table 6). Except for the group of identified DEGs encoding superoxide dismutase, the vast majority of DEGs from the other two groups showed lower expression levels in root tissue of G.935 than in that of B.9.

3.6. DEGs with the Annotated Function as Transcription Factors (TF). Transcription factors (TFs) are the key regulator of cellular transcriptional activities, and several TF families are well known for their roles in defense response such as MYB (myeloblastosis oncogene), ERF (ethylene response factor), and WRKY (containing signature WRKY amino acid residues) families $[26,27]$. From this data set DEGs encoding proteins belonging to several families of TFs showed considerable variation at the expression levels between two cultivars (Figure 1). The comparative transcript abundance demonstrated specific patterns for each TF family. For example, most bHLH, WRKY, and ERF-encoding genes

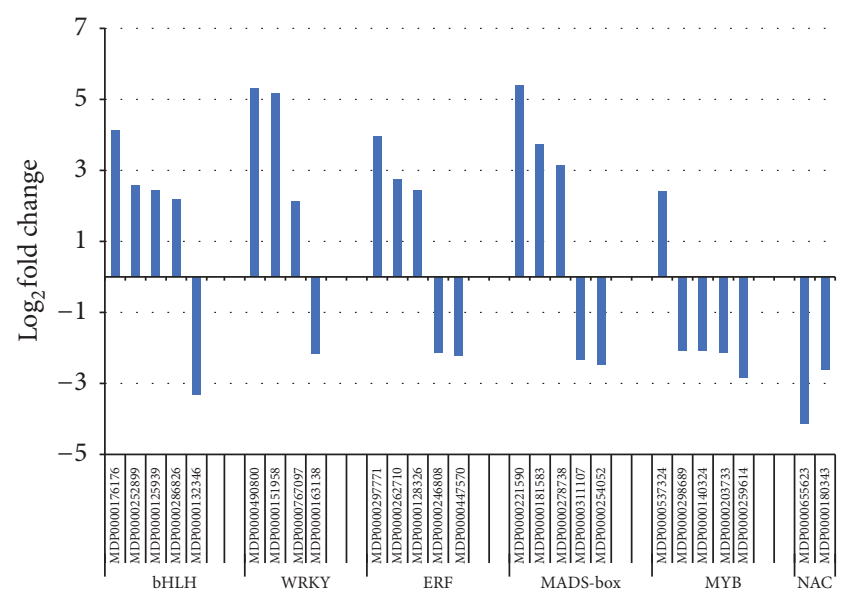

FIGURE 1: Identified DEGs encoding TF families implicated in defense responses. Gene reference numbers and the TF family names were shown on the $x$-axis; $\log _{2}$ FC values were indicated on the $y$ axis, where positive values mean the higher transcript level in the roots of G.935 over that of B.9; the opposite is for the negative $\log _{2} \mathrm{FC}$ values. 
TABLE 4: DEGs encoding lectin receptor kinases and glutamate receptors.

\begin{tabular}{|c|c|c|}
\hline Apple gene model $^{\mathrm{a}}$ & Functional annotations $^{\mathrm{b}}$ & $\log _{2} \mathrm{FC}^{\mathrm{c}}$ \\
\hline \multicolumn{3}{|c|}{ L-type lectin-domain containing receptor kinase } \\
\hline MDP0000142818 & L-type lectin-RLK; IV.1-like & +5.5 \\
\hline MDP0000226962 & L-type lectin-RLK; L-type lectin-RLK X.1 & +2.5 \\
\hline MDP0000265486 & L-type lectin-RLK; IX.1-like [Malus domestica] & +5.4 \\
\hline MDP0000305188 & L-type lectin-RLK; IX.1-like & +4.1 \\
\hline MDP0000176219 & L-type lectin-RLK; IX.1-like & +4.0 \\
\hline MDP0000199947 & L-type lectin-RLK, IX.1-like & +2.1 \\
\hline MDP0000130183 & L-type lectin-RLK, S.1-like & -3.3 \\
\hline MDP0000133353 & L-type lectin-RLK, S.4-like & +2.6 \\
\hline MDP0000200920 & L-type lectin-RLK, S.4-like & -4.0 \\
\hline MDP0000145928 & L-type lectin-RLK, VIII.2-like & -3.2 \\
\hline \multicolumn{3}{|c|}{ G-type lectin S-receptor-like serine/threonine-protein kinase } \\
\hline MDP0000297547 & G-type lectin SRK, Atlg11410 & +3.9 \\
\hline MDP0000303074 & G-type lectin SRK, Atlg11410 & +3.7 \\
\hline MDP0000930643 & G-type lectin SRK, Atlg11410 isoform X1 & +6.0 \\
\hline MDP0000296847 & G-type lectin SRK, Atlg11410 isoform X2 & +2.0 \\
\hline MDP0000263753 & G-type lectin SRK, Atlg61500 & +2.2 \\
\hline MDP0000278380 & G-type lectin SRK, Atlg61500 & +2.5 \\
\hline MDP0000212928 & G-type lectin SRK, Atlg61500 & +2.4 \\
\hline MDP0000550024 & G-type lectin SRK, Atlg61550 & +2.5 \\
\hline MDP0000172360 & G-type lectin SRK, Atlg61550 & -2.3 \\
\hline MDP0000204472 & G-type lectin SRK, Atlg61550 & -2.9 \\
\hline MDP0000936164 & G-type lectin SRK, Atlg67520 & +6.0 \\
\hline MDP0000284325 & G-type lectin SRK, At2g19130 & +3.0 \\
\hline MDP0000654452 & G-type lectin SRK, At2g19130 & +2.4 \\
\hline MDP0000314519 & G-type lectin SRK, At4g27290 & +2.3 \\
\hline MDP0000189422 & G-type lectin SRK, At4g27290 & +2.1 \\
\hline MDP0000281186 & G-type lectin SRK, At4g27290 isoform X1 & -2.6 \\
\hline MDP0000213485 & G-type lectin SRK, At4g27290 isoform X5 & -2.3 \\
\hline MDP0000293905 & G-type lectin SRK, RKS1 & 2.6 \\
\hline MDP0000314952 & G-type lectin SRK, RKS1, isoform X4 & -2.9 \\
\hline MDP0000288873 & G-type lectin SRK, RLK1 & +4.7 \\
\hline MDP0000189901 & G-type lectin SRK, RLK1 & +4.7 \\
\hline MDP0000217223 & G-type lectin SRK, RLK1 & +3.2 \\
\hline MDP0000627319 & G-type lectin SRK, RLK1 & +3.2 \\
\hline MDP0000322228 & G-type SRK, RLK1 & +3.2 \\
\hline MDP0000310978 & G-type lectin SRK, SD1-1 & -4.4 \\
\hline \multicolumn{3}{|l|}{ Glutamate receptor } \\
\hline MDP0000176838 & Glutamate receptor 1.3-like & +2.2 \\
\hline MDP0000314708 & Glutamate receptor 2.2-like & +2.3 \\
\hline MDP0000450755 & Glutamate receptor 2.2-like & -3.1 \\
\hline MDP0000771031 & Glutamate receptor 2.7-like & +2.7 \\
\hline MDP0000318184 & Glutamate receptor 2.7-like & +2.3 \\
\hline MDP0000220955 & Glutamate receptor 2.8-like & +4.8 \\
\hline MDP0000291967 & Glutamate receptor 2.8-like & -2.6 \\
\hline MDP0000228982 & Glutamate receptor 2.8-like & -2.9 \\
\hline MDP0000255245 & Glutamate receptor 2.8-like & -4.4 \\
\hline MDP0000154359 & Glutamate receptor 2.8-like & -4.7 \\
\hline
\end{tabular}


TABLE 4: Continued.

\begin{tabular}{|c|c|c|}
\hline Apple gene model $^{\mathrm{a}}$ & Functional annotations $^{\mathrm{b}}$ & $\log _{2} \mathrm{FC}^{\mathrm{c}}$ \\
\hline MDP0000307622 & Glutamate receptor 3.4-like & +5.2 \\
\hline MDP0000199967 & Glutamate receptor 3.4-like & +4.9 \\
\hline MDP0000307121 & Glutamate receptor 3.4-like & +4.2 \\
\hline MDP0000487438 & Glutamate receptor 3.6-like & +2.0 \\
\hline
\end{tabular}

TABLE 5: DEGs encoding other receptor kinases and receptor-like proteins.

\begin{tabular}{lcc}
\hline Receptor groups & $\begin{array}{c}\text { Number of DEGs with } \\
\text { higher transcript abundance } \\
\text { in G.935 }\end{array}$ & $\begin{array}{c}\text { Number of DEGs with } \\
\text { lower transcript abundance } \\
\text { in G.935 }\end{array}$ \\
\hline LRR receptor-like serine/threonine-protein kinase & 68 & 37 \\
Receptor-like protein kinase & 42 & 14 \\
Receptor-like protein & 36 & 8 \\
Cysteine-rich receptor-like protein kinase & 12 & 5 \\
\hline
\end{tabular}

TABLE 6: DEGs with the annotated function of oxidation and reduction processes.

\begin{tabular}{|c|c|c|}
\hline Gene model $^{\mathrm{a}}$ & Functional annotations $^{\mathrm{b}}$ & $\log _{2} \mathrm{FC}^{\mathrm{c}}$ \\
\hline \multicolumn{3}{|c|}{ Glutathione S-transferase } \\
\hline MDP0000183814 & Glutathione S-transferase & +2.1 \\
\hline MDP0000138709 & Glutathione S-transferase & -2.0 \\
\hline MDP0000161008 & Glutathione S-transferase parA & -2.2 \\
\hline MDP0000175866 & Glutathione S-transferase parA & -2.4 \\
\hline MDP0000276730 & Glutathione S-transferase U8-like & -2.8 \\
\hline MDP0000252292 & Glutathione S-transferase F12-like & -4.4 \\
\hline \multicolumn{3}{|l|}{ Peroxidase } \\
\hline MDP0000203927 & Glutathione peroxidase 8 isoform X1 & +4.8 \\
\hline MDP0000455043 & Peroxidase A2-like, partial & +2.4 \\
\hline MDP0000269302 & Peroxidase 60-like & +2.2 \\
\hline MDP0000451182 & Peroxidase 66-like & +2.0 \\
\hline MDP0000493703 & Peroxidase N1-like & -2.2 \\
\hline MDP0000283650 & Peroxidase & -2.3 \\
\hline MDP0000684133 & Peroxidase N1-like & -2.4 \\
\hline MDP0000233961 & Peroxidase A2-like & -2.5 \\
\hline MDP0000668551 & Peroxidase N1-like & -2.5 \\
\hline MDP0000166657 & Peroxidase 51-like & -2.6 \\
\hline MDP0000338065 & Glutathione peroxidase isoform X1 & -2.9 \\
\hline MDP0000173751 & Peroxidase 59-like & -2.9 \\
\hline MDP0000206714 & Peroxidase N1-like & -3.1 \\
\hline MDP0000298916 & Peroxidase 4 -like isoform $\mathrm{X} 1$ & -3.1 \\
\hline MDP0000494230 & Peroxidase N-like & -3.9 \\
\hline MDP0000172233 & Peroxidase 50-like & -4.2 \\
\hline MDP0000212661 & Glutathione peroxidase isoform $\mathrm{X} 1$ & -5.4 \\
\hline MDP0000580571 & Peroxidase N-like & -5.4 \\
\hline
\end{tabular}




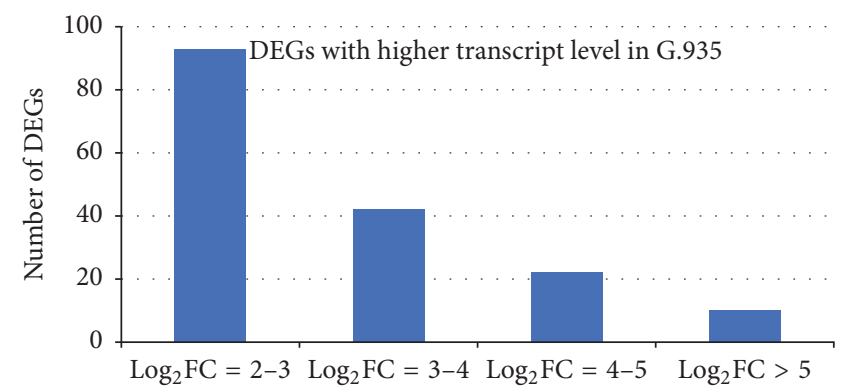

(a)

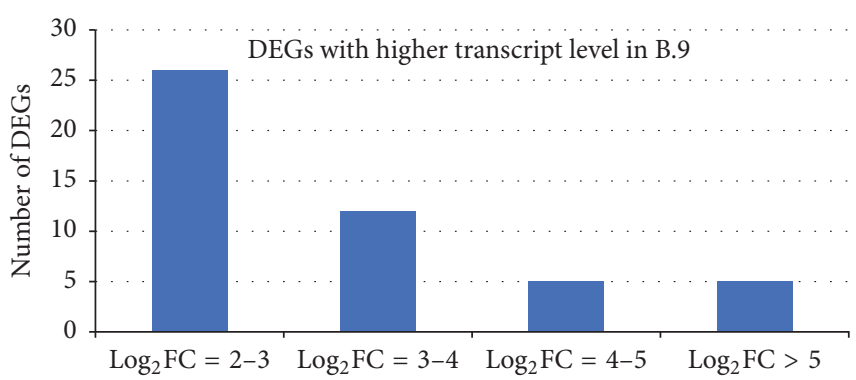

(b)

Figure 2: The number and the range of $\log _{2} \mathrm{FC}$ values for identified R-genes with higher expression levels in G.935 (a) and B.9 (b). For both cultivars, more genes exhibited moderate transcript level variation with $\log _{2}$ FC at 2-3. Relative small number showed significant variations of transcript abundance as compared with other cultivar. Detailed information was shown in Supplementary File.
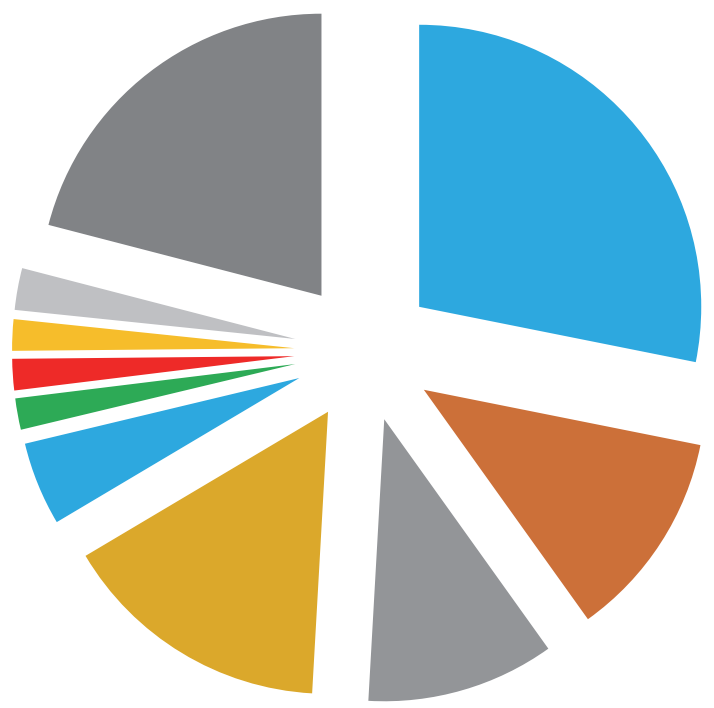

Total R-genes with higher expression level in G.935: 167

- TMV R protein $\mathrm{N}$

- TIR-NBS-LRR R protein

- CC-NBS-IRR R protein

- R protein RGA2- (or 3 and 4) like

- $\mathrm{R}$ protein RPP8 or 13-like protein 1

- R protein $\mathrm{SNC1}$
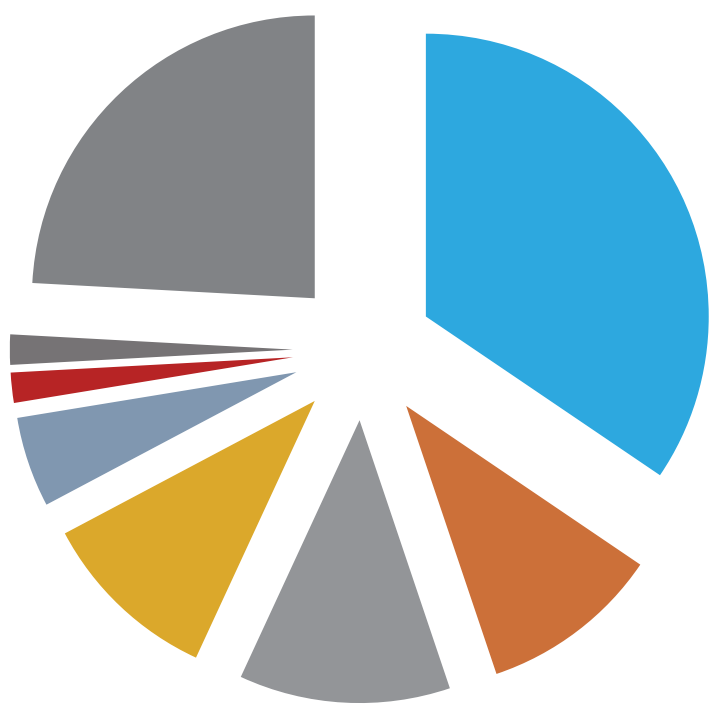

Total R-genes with lower expression level in B.9: 59
- TMV R protein $\mathrm{N}$

- TIR-NBS-LRR R protein

- CC-NBS-IRR R protein

- R protein RGA2- (or 3 and 4) like
- R protein RPP8 or 13-like protein 1

- R protein At4g19050

- R protein At4g27190-like

- Others

(b)

FIGURE 3: Classification for identified DEGs encoding resistance proteins. An overall similarity for the subcategories of R protein encoding genes which are with higher expression level in either B.9 or G.935 was observed. However, three times more DEGs were identified from G.935 as compared to that from B.9. A few subcategories R protein encoding genes were unique in each cultivar such as R protein SNC1 from G.935 and R protein At4g19050 from B.9.

showed higher transcript level in the roots of G.935, but a majority or all of identified MYB and NAC encoding DEGs showed opposite patterns with higher transcript level in the roots of B.9.

3.7. DEGs Annotated as Resistance Genes. A large number of R-genes were identified as DEGs by comparing root transcriptome between the resistant cultivar G.935 and the susceptible cultivar B.9. As shown in Figures 2(a) and 2(b) (and see details in Supplementary File number 1), fifty-nine identified R-genes showed higher expression level in susceptible B.9 (than in G.935); in contrast, 167 DEGs showed elevated transcript levels in the roots of the resistant cultivar G.935; the number of identified DEGs is almost 3 times larger than those identified from B.9. However, the distribution pattern among subcategories of annotated R-gene based on $\log _{2} \mathrm{FC}$ values is comparable. According to their functional annotation, it appears that similar subcategories of $\mathrm{R}$ protein encoding genes were identified, with higher transcript level in either cultivar (Figures 3(a) and 3(b)). "TMV resistance protein 


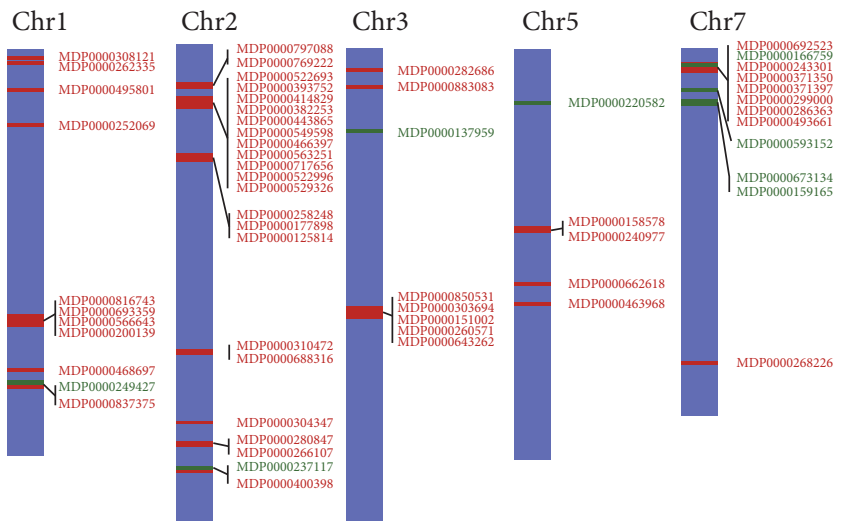

(a)



(b)

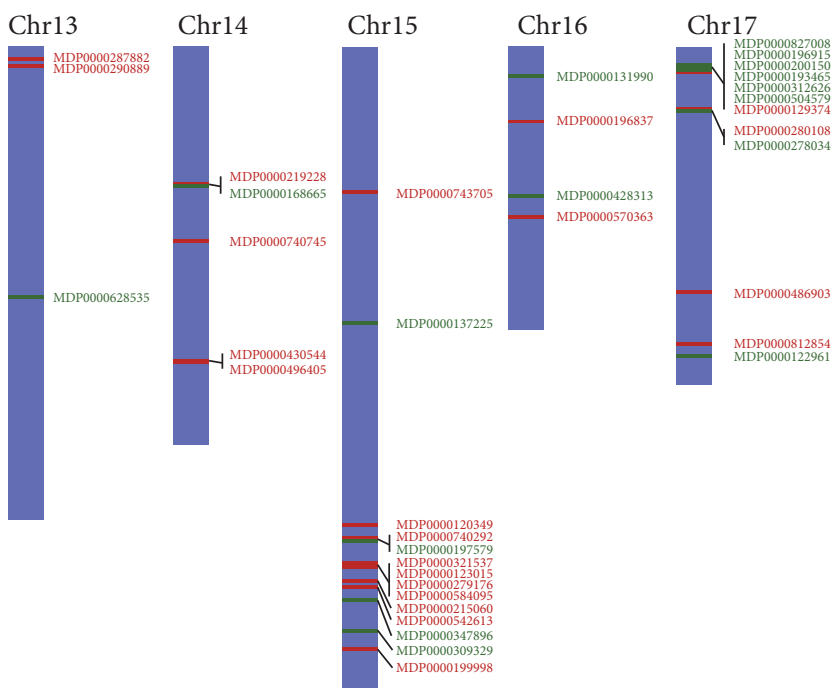

(c)

Figure 4: Chromosome locations of identified R-genes. The numbers on top of purple bars denote various apple chromosomes. MDP numbers highlighted in red indicate those with higher transcript level in the resistant cultivar G.935; MDP numbers highlighted in green indicate lower transcript level in G.935. Some of the identified R-genes have not localized to a specific chromosome.

$\mathrm{N}$-like" R-genes are the most prevalent group, with $28 \%$ and $34 \%$ of all identified R-genes showing higher expression level in G.935 and B.9, respectively. CC-NBS-LRR resistance protein encoding genes, TIR-NBS-LRR resistance protein encoding genes, and disease resistance protein RGA2 (or 3, 4, and 8) are the other major subcategories which contain the double-digit percentage to total identified R-genes. Three small groups of DEGs, those encoded proteins similar to "SUPPRESSOR of nprl-1, CONSTITUTIVE 1-like," "R protein Atlg50180," and "R protein At3g14460," were identified only from G.935 as DEGs with higher transcript levels. In contrast, two small groups, "At4g19050 R protein" and "At4g27190-like R protein" encoding genes were identified only from B.9 roots with higher transcript levels. The chromosomal locations of these R-genes showed the typical clustered pattern of R-gene distribution along most of the 17 apple chromosomes (Figure 4).
3.8. DEGs Encoding PR Proteins, Cell Wall Metabolism, and Secondary Metabolism. As shown in Table 7, genes encoding four classes of pathogenesis-related (PR) proteins showed differential expression patterns between two cultivars, but the patterns varied for each class. Two genes encoding "pathogenesis-related protein 1-like" and four out of five identified "thaumatin-like protein" encoding genes showed higher expression level in G.935; conversely, four "chitinase" genes and three "glucan endo-1,3-beta-glucosidase" genes all exhibited lower expression level in G.935. All 11 cell wall metabolisms related genes except one in three groups, that is, "pectin esterase inhibitor," "polygalacturonase," and "cellulose synthase-like protein" encoding genes, demonstrated the higher expression level in G.935, as compared with that in B.9. Plant secondary metabolisms were well-demonstrated to be a part of induced defense response in many pathosystems [28-31]. Although DEGs encoding proteins belonging to at 
TABLE 7: DEGs encoding pathogenesis-related proteins and cell wall metabolism enzymes.

\begin{tabular}{|c|c|c|}
\hline Apple gene model $^{\mathrm{a}}$ & Functional annotations $^{\mathrm{b}}$ & $\log _{2} \mathrm{FC}^{\mathrm{c}}$ \\
\hline \multicolumn{3}{|c|}{ Pathogenesis-related protein 1-like } \\
\hline MDP0000202342 & Pathogenesis-related protein 1-like & +5.5 \\
\hline MDP0000144351 & Pathogenesis-related protein 1-like & +3.8 \\
\hline \multicolumn{3}{|c|}{ Chitinase family protein } \\
\hline MDP0000202342 & Chitinase family protein & -3.2 \\
\hline MDP0000144351 & Chitinase family protein & -2.9 \\
\hline MDP0000171646 & Acidic endochitinase SE2-like & -2.6 \\
\hline MDP0000282918 & Acidic mammalian chitinase-like & -2.1 \\
\hline \multicolumn{3}{|l|}{ Thaumatin-like protein } \\
\hline MDP0000916930 & Thaumatin-like protein la & +4.9 \\
\hline MDP0000205389 & Thaumatin-like protein la & +2.9 \\
\hline MDP0000552328 & Thaumatin-like protein la & +2.3 \\
\hline MDP0000218699 & Thaumatin-like protein la & +2.1 \\
\hline MDP0000293451 & Thaumatin-like protein 1-like & +2.1 \\
\hline MDP0000124752 & Thaumatin-like protein la & -3.3 \\
\hline \multicolumn{3}{|c|}{ Glucan endo-1,3-beta-glucosidase } \\
\hline MDP0000908326 & Glucan endo-1,3-beta-glucosidase 9-like & -2.2 \\
\hline MDP0000231628 & Glucan endo-1,3-beta-glucosidase 4-like & -2.0 \\
\hline MDP0000237685 & Glucan endo-1,3-beta-glucosidase 12-like & -5.8 \\
\hline \multicolumn{3}{|l|}{ Pectin esterase inhibitor } \\
\hline MDP0000188907 & Pectin esterase inhibitor 16 & +3.1 \\
\hline MDP0000161463 & Pectin esterase inhibitor 35 & +3.0 \\
\hline MDP0000299506 & Pectin esterase inhibitor 24 & +2.5 \\
\hline MDP0000611653 & Pectin esterase inhibitor 24 & +2.4 \\
\hline MDP0000299884 & Pectin esterase inhibitor 24 & +2.2 \\
\hline MDP0000503248 & Pectin esterase inhibitor family protein & +3.0 \\
\hline \multicolumn{3}{|l|}{ Polygalacturonase } \\
\hline MDP0000845683 & Polygalacturonase & +2.3 \\
\hline MDP0000845685 & Polygalacturonase & +2.6 \\
\hline \multicolumn{3}{|c|}{ Cellulose synthase-like protein } \\
\hline MDP0000208533 & Cellulose synthase-like protein E2 & +4.1 \\
\hline MDP0000172542 & Cellulose synthase-like protein G3 & +2.4 \\
\hline MDP0000223480 & Cellulose synthase-like protein E1 & -2.1 \\
\hline
\end{tabular}

least thirteen gene families of enzymes with the implication of functioning in plant secondary metabolisms were identified, nevertheless, between two cultivars a relative comparable status was observed in terms of the number of DEGs showing either higher or lower transcript levels (Table 8; Supplementary File number 1).

3.9. Validation of the Expression Patterns of Selected DEGs by $q R T-P C R$. The expression patterns for nine DEGs identified by RNA-seq based comparative transcriptome analysis were validated by an independent approach of qRT-PCR (Figure 5). Gene specific primer sets, reference numbers in the apple genome database, and the RNA-seq data are shown in Supplementary File number 2. Although RNA-seq and qRT-PCR utilize different algorithms in quantifying their expression levels and huge variation of transcript abundance between two cultivars exist for some selected genes, most of the tested DEGs showed the consistency in dynamic gene expression patterns (Figure 4).

\section{Discussion}

In this study, the comparative analysis of the transcriptomes of two apple rootstock cultivars, a susceptible B.9 and a 
TABLE 8: Genes encoding proteins functioning in secondary metabolism.

\begin{tabular}{lcc}
\hline Gene families $^{\text {a }}$ & $\begin{array}{c}\text { Number of DEGs with } \\
\text { higher } \begin{array}{c}\text { transcript abundance } \\
\text { in G.935 }\end{array}\end{array}$ & $\begin{array}{c}\text { Number of DEGs with } \\
\text { lower transcript abundance } \\
\text { in G.935 }\end{array}$ \\
\hline $\begin{array}{l}\text { UDP-glucose flavonoid 3-O-glucosyltransferase } \\
\text { 7-like }\end{array}$ & 1 & 1 \\
4-Hydroxybenzoategeranyl transferase 2-like & 1 & 0 \\
Phenylalanine ammonia-lyase class 1-like & 1 & 0 \\
Phytoene synthase 2, chloroplastic-like & 2 & 0 \\
Squalene monooxygenase-like & 2 & 0 \\
Isoflavone reductase homolog & 1 & 4 \\
3-Ketoacyl-CoA synthase-like & 1 & 5 \\
Cinnamoyl-CoA reductase 1-like & 3 & 3 \\
Geraniol 8-hydroxylase-like & 0 & 2 \\
Caffeic acid 3-O-methyl transferase-like & 3 & 0 \\
Flavonoid 3'-monooxygenase-like & 4 & 9 \\
UDP-glycosyl transferase-like & 14 & 9 \\
Beta-glucosidase & 14 & \\
\hline
\end{tabular}

${ }^{\mathrm{a}}$ Function annotation is based on the blastX search against NR database in GenBank.

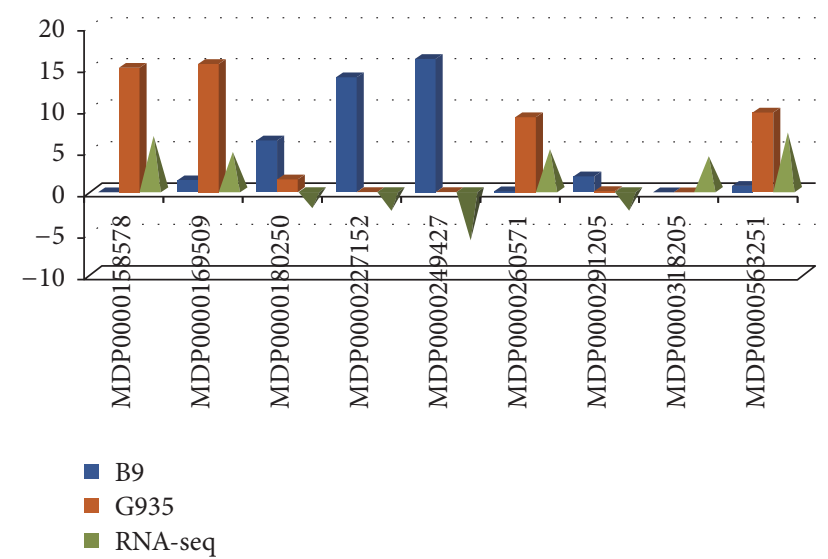

FIGURE 5: Validation of differential expression patterns for selected DEGs by qRT-PCR. Validation of the expression patterns for selected DEGs using qRT-PCR. Gene reference numbers were shown on the $x$-axis; blue and red bars show the relative expression level in the roots of B.9 and G.935 from qRT-PCR experiment; the green pyramid indicates the values of $\log _{2}$ FC from RNA-seq data; the upward direction represents the higher transcript level in the roots of G.935 and downward direction indicates lower transcript level in G.935. Values on the $y$ axis denote the relative expression level for qRT-PCR and the $\log _{2}$ FC values from RNA-seq data set.

resistant G.935, under no pathogenic pressure, uncovered a wide spectrum of DEGs that were annotated as genes related to the plant host defense system. Previously, contrasting resistance phenotypes were demonstrated to exist between these two cultivars when they were challenged by the soilborne pathogen of $P$. ultimum [11]. Interestingly, the current data set indicated that a preformed defense system exists in the root tissues of resistant cultivar G.935, but not susceptible B.9. Notably, because a synchronized tissue culture procedure was performed in preparing the plants with equivalent developmental stage between these two cultivars and these plants were maintained under identical conditions (light cycle, watering schedule, and environmental temperature) with minimized stress, such profound differences at the transcriptome level seem unlikely to be caused by factors other than genetics.

Intraspecific gene expression variation, or expression level polymorphism (ELP), is known to be a common phenomenon [32-34]. Among rice germplasm accessions, a strong correlation was observed between phenotypes partially resistant to rice pathogen Magnaporthe oryzae and a preformed proactive defense system [12]. Higher gene expression levels and enzymatic activities related to defense responses were also observed in uninoculated kernels of disease resistant maize lines, interpreted as conferring a major readiness to the pathogen attack [13]. In another study, a large number of differentially expressed defense-related genes were identified between two near-isogenic lines of Brassica rapa at 0-hour postinoculation (hpi), that is, before encountering the pathogen Plasmodiophora brassicae [32]. Therefore, preformed defense due to constitutive expression of defense-related genes may commonly exist, although the underlying mechanism(s) causing such sustained and elevated expression of defense-related genes has not been well elucidated.

In an attempt to explain the mechanism potentially regulating preformed defense, Vergne et al. [12] proposed the "leakage" theory, in that an oversensitive regulator upstream of resistance pathways genes may be constantly agitated by some environmental factor(s) and that overactivated defense pathways would then lead to enhanced levels even in the absence of infection. Alternatively, a weak or "loss of function" allele for a "susceptibility" gene, or a negative regulator of resistance, upstream of a signal transduction pathway may 
result in wide-ranging transcriptome reprogramming. The broad-spectrum resistance from the recessive alleles of the barley MLO gene, a negative regulator of disease resistance, was believed to cause the constitutive expression of some disease resistance genes, even causing spontaneous HR-like cell-death $[35,36]$. Specific to plant roots, the possibility exists, although perhaps less likely, that the unintentional introduction of an endophyte or even exterior biological or abiotic factor in the soil could trigger differential regulation of plant defense system genes in different genotypes. Recently it was reported that activation of pathways of secondary metabolism, which is involved in plant defense in the root of grapevine, was likely resulting from the colonization by endophytic bacteria [37].

Wide-spread and constitutive activation of multiple aspects of the plant defense system seems to be contradictory to the fitness cost for a plant species, as induced defense responses are generally believed to save energy under a pathogen-free environment. Nevertheless, it was also proposed by van Hulten et al. [38] that the benefits of primingmediated resistance could outweigh its energy cost, assuming a high and constant pressure from the pathogen. This assumption could possibly apply to the root of a perennial plant, like apple, where the cumulative soilborne necrotrophic pathogens in the soil from long-life cycle fruit trees are a constant threat to the health of root system.

In the induced defense response, plants use discrete hormone balances and fine-tuned crosstalk to tailor specific reactions toward different types of attacking pathogens. It is well established that biosynthesis and signaling of ethylene (ET) and jasmonic acid (JA) are essential for plant defense responses toward necrotrophic pathogens [17, 18, 39-41]. Transcription factors (TFs) are the master-control proteins for swift transcriptional regulation during plant-pathogen interactions [26, 27]. For example, JA-inducible R2R3-MYB (myeloblastosis oncogene), ERF, and WRKY (containing signature WRKY amino acid residues) are known to be the key regulators in activating the phenylpropanoid biosynthetic pathway and expression of resistance genes $[42,43]$. From the current data set, constitutive expressions for several defense hormone biosynthesis genes, and defense implicated TFs, were shown to have elevated transcript abundance in the root of the disease resistant cultivar G.935 as compared to that of the susceptible B.9 cultivar in the absence of pathogens (this paper). Also, it seems that different members from the same gene families, for example, the ACS gene family, are functioning in either preformed defense system or inducible defense activation $[44,45]$.

$\mathrm{R}$ protein encoding genes represent one of the groups with large number of DEGs identified from the present study. $\mathrm{R}$ proteins typically contain nucleotide-binding (NB) and leucine-rich repeat (LRR) domains and belong to a class of proteins known as NB-LRRs. These proteins can be further divided into two main groups based on their N-terminal domains $[1,46-48]$. The first group possesses an $\mathrm{N}$-terminal domain with sequence similarity to the intracellular signaling domains of the Drosophila Toll and mammalian interleukin(IL-) 1 receptors and is referred to as TIR-NB-LRRs or TNLs. The second group is collectively known as CC-NB-LRRs or CNLs, based on the presence of a predicted N-terminal coiled-coil domain in some, but not all, members of this class. The tobacco mosaic virus resistance gene, $\mathrm{N}$, encodes a TIR-NB-LRR class of resistance protein [49]. Although the repertoires of the large number of NB-LRR genes can be predicated based on increasing available genome sequences, the respective differential regulation patterns of these R-genes in different tissues and between specific genotypes within a species are very limited. Our data set indicated that a two to one ratio of R-genes exhibited higher levels of expression in G.935 than those with lower expression levels, as compared to the same genes of susceptible cultivar B.9. The large number of identified R-genes may be partly due to capability of extensive expression variations at the genomewide scale by RNAseq technology. Nevertheless, all identified DEGs, using $-2<$ $\log _{2} \mathrm{FC}>2$ as cutoff, represent only about $3 \%$ of the apple genomes based on the predicted number of gene models; and defense-related genes are a small portion of all DEGs.

Many questions remain to be answered: What is the "central switch" upstream of defense system that turns on the numerous defense-related genes? Is epigenetic alteration among genotypes within a species a possible mechanism impacting the transcriptome? [50-52] Admittedly, the observations from the current study are limited to the difference at the transcript level; therefore, we must ask whether the elevated transcript level corresponds to enrichment of, respectively, encoded proteins. Are there any detrimental effects with respect to other aspects of development of the resistant G.935, due to the observed constitutive expression of defenserelated genes? Overall the results from the current study provide a comprehensive overview into the root of a resistant and susceptible apple plant and offer a novel perspective to evaluate the roles of preformed defense to soilborne pathogens. Some of the identified genes, particularly those functioning upstream of the defense activation process, will be tested in further work to determine their robustness across rootstock germplasms with defined resistance traits; the nucleotide sequences of tested genes should make possible the development of molecular tools useful for breeders, to efficiently and accurately incorporate the resistance traits into new generations of apple rootstocks.

\section{Conclusion}

Although intraspecific gene expression level polymorphism (ELP) is a common phenomenon, it was somewhat unexpected that large numbers of defense-related genes and/or disease resistance genes were differentially regulated in the absence of pathogen infection in the roots of two apple rootstock genotypes. The identified DEGs encode proteins that encompass multiple functional groups in defense response, such as PRR for pathogen detection, proteins for defense hormone biosynthesis and signaling, TFs with known roles in defense activation, enzymes in secondary metabolism, and various classes of $\mathrm{R}$ proteins. Although numerous different allelotypes may exist for most apple genes due to high level heterogeneity of the apple genome [53], the breadth and the intensity of the differentially expressed, defense-related genes in the root tissue of the resistant cultivar of G.935 deserve 
additional careful experimentation. Better understanding of preformed defense, and of its potential to contribute to an overall disease resistance phenotype in a perennial fruit tree, could present novel opportunities for future crop improvement.

\section{Disclosure}

Mention of trade names or commercial products in this publication is solely for the purpose of providing specific information and does not imply recommendation or endorsement by the U.S. Department of Agriculture.

\section{Conflicts of Interest}

The authors declare that the research was conducted in the absence of any commercial or financial relationships that could be construed as potential conflicts of interest.

\section{Authors' Contributions}

Yanmin Zhu and Jonathan Shao contributed equally. All authors read and approved the final manuscript.

\section{Acknowledgments}

This work was supported by USDA base fund and the research fund from Washington Tree Fruit Research Commission. The authors thank Melody Saltzgiver, Connor Foli, and Edward Valdez for their excellent technical assistance.

\section{References}

[1] J. D. G. Jones and J. L. Dangl, "The plant immune system," Nature, vol. 444, no. 7117, pp. 323-329, 2006.

[2] P. N. Dodds and J. P. Rathjen, "Plant immunity: towards an integrated view of plant-pathogen interactions," Nature Reviews Genetics, vol. 11, no. 8, pp. 539-548, 2010.

[3] J. L. Dangl, D. M. Horvath, and B. J. Staskawicz, "Pivoting the plant immune system from dissection to deployment," Science, vol. 341, no. 6147, pp. 746-751, 2013.

[4] Y. Jamir, M. Guo, H.-S. Oh et al., "Identification of Pseudomonas syringae type III effectors that can suppress programmed cell death in plants and yeast," Plant Journal, vol. 37, no. 4, pp. 554$565,2004$.

[5] P. He, L. Shan, N.-C. Lin et al., "Specific bacterial suppressors of MAMP signaling upstream of MAPKKK in arabidopsis innate immunity," Cell, vol. 125, no. 3, pp. 563-575, 2006.

[6] K. Nomura, S. DebRoy, Y. H. Lee, N. Pumplin, J. Jones, and S. Y. He, "A bacterial virulence protein suppresses host innate immunity to cause plant disease," Science, vol. 313, no. 5784, pp. 220-223, 2006.

[7] T. Boller and S. Y. He, "Innate immunity in plants: an arms race between pattern recognition receptors in plants and effectors in microbial pathogens," Science, vol. 324, no. 5928, pp. 742-743, 2009.

[8] F. N. Martin and J. E. Loper, "Soilborne plant diseases caused by Pythium spp. ecology, epidemiology, and prospects for biological control," Critical Reviews in Plant Sciences, vol. 18, no. 2, pp. 111-181, 1999.
[9] S. Kamoun, O. Furzer, J. D. G. Jones et al., "The Top 10 oomycete pathogens in molecular plant pathology," Molecular Plant Pathology, vol. 16, no. 4, pp. 413-434, 2015.

[10] M. Mazzola, "Elucidation of the microbial complex having a causal role in the development of apple replant disease in Washington," Phytopathology, vol. 88, no. 9, pp. 930-938, 1998.

[11] Y. Zhu, S. Shin, and M. Mazzola, "Genotype responses of two apple rootstocks to infection by Pythium ultimum causing apple replant disease," Canadian Journal of Plant Pathology, vol. 38, no. 4, pp. 483-491, 2016.

[12] E. Vergne, X. Grand, E. Ballini et al., "Preformed expression of defense is a hallmark of partial resistance to rice blast fungal pathogen Magnaporthe oryzae," BMC Plant Biology, vol. 10, article 206, 2010.

[13] A. Lanubile, V. Maschietto, S. De Leonardis, P. Battilani, C. Paciolla, and A. Marocco, "Defense responses to mycotoxinproducing fungi Fusarium proliferatum, F. subglutinans, and Aspergillus flavus in kernels of susceptible and resistant maize genotypes," Molecular Plant-Microbe Interactions, vol. 28, no. 5, pp. 546-557, 2015.

[14] B. Langmead and S. L. Salzberg, "Fast gapped-read alignment with Bowtie 2," Nature Methods, vol. 9, no. 4, pp. 357-359, 2012.

[15] S. F. Altschul, W. Gish, W. Miller, E. W. Meyers, and D. J. Lipman, "Basic local alignment search tool," Journal of Molecular Biology, vol. 215, no. 3, pp. 403-410, 1990.

[16] K. J. Livak and T. D. Schmittgen, "Analysis of relative gene expression data using real-time quantitative PCR and the $2^{- \text {DDCT }}$ method," Methods, vol. 25, pp. 402-408, 2001.

[17] J. Browse, "Jasmonate passes muster: a receptor and targets for the defense hormone," Annual Review of Plant Biology, vol. 60, pp. 183-205, 2009.

[18] A. Robert-Seilaniantz, M. Grant, and J. D. G. Jones, "Hormone crosstalk in plant disease and defense: more than just Jasmonate-salicylate antagonism," Annual Review of Phytopathology, vol. 49, pp. 317-343, 2011.

[19] A. Miya, P. Albert, T. Shinya et al., "CERK1, a LysM receptor kinase, is essential for chitin elicitor signaling in Arabidopsis," Proceedings of the National Academy of Sciences of the United States of America, vol. 104, no. 49, pp. 19613-19618, 2007.

[20] X.-C. Zhang, X. Wu, S. Findley et al., "Molecular evolution of lysin motif-type receptor-like kinases in plants," Plant Physiology, vol. 144, no. 2, pp. 623-636, 2007.

[21] P. Singh and L. Zimmerli, "Lectin receptor kinases in plant innate immunity," Frontiers in Plant Science, vol. 4, article 124, 2013.

[22] K. Bouwmeester and F. Govers, "Arabidopsis L-type lectin receptor kinases: phylogeny, classification, and expression profiles," Journal of Experimental Botany, vol. 60, no. 15, pp. 43834396, 2009.

[23] B. G. Forde and M. R. Roberts, "Glutamate receptor-like channels in plants: a role as amino acid sensors in plant defence?" F1000Prime Reports, vol. 6, article 37, 2014.

[24] M. B. Price, J. Jelesko, and S. Okumoto, "Glutamate receptor homologs in plants: functions and evolutionary origins," Frontiers in Plant Science, vol. 3, article 235, 2012.

[25] F. Van Breusegem and J. F. Dat, "Reactive oxygen species in plant cell death," Plant Physiology, vol. 141, no. 2, pp. 384-390, 2006.

[26] S. R. Ramirez and C. Basu, "Comparative analyses of plant transcription factor databases," Current Genomics, vol. 10, no. 1, pp. 10-17, 2009. 
[27] J. L. Riechmann, J. Heard, G. Martin et al., "Arabidopsis transcription factors: genome-wide comparative analysis among eukaryotes," Science, vol. 290, no. 5499, pp. 2105-2110, 2000.

[28] P. Bednarek, "Chemical warfare or modulators of defence responses-the function of secondary metabolites in plant immunity," Current Opinion in Plant Biology, vol. 15, no. 4, pp. 407-414, 2012.

[29] E. E. Rogers, J. Glazebrook, and F. M. Ausubel, "Mode of action of the Arabidopsis thaliana phytoalexin camalexin and its role in Arabidopsis-pathogen interactions," Molecular Plant-Microbe Interactions, vol. 9, no. 8, pp. 748-757, 1996.

[30] A. Sellam, B. Iacomi-Vasilescu, P. Hudhomme, and P. Simoneau, "In vitro antifungal activity of brassinin, camalexin and two isothiocyanates against the crucifer pathogens Alternaria brassicicola and Alternaria brassicae," Plant Pathology, vol. 56, no. 2, pp. 296-301, 2007.

[31] R. J. Grayer and T. Kokubun, "Plant-fungal interactions: the search for phytoalexins and other antifungal compounds from higher plants," Phytochemistry, vol. 56, no. 3, pp. 253-263, 2001.

[32] C. Delker and M. Quint, "Expression level polymorphisms: heritable traits shaping natural variation," Trends in Plant Science, vol. 16, no. 9, pp. 481-488, 2011.

[33] A. Druka, E. Potokina, Z. Luo et al., "Expression quantitative trait loci analysis in plants," Plant Biotechnology Journal, vol. 8, no. 1, pp. 10-27, 2010.

[34] D. Kliebenstein, "Quantitative genomics: analyzing intraspecific variation using global gene expression polymorphisms or eQTLs," Annual Review of Plant Biology, vol. 60, pp. 93-114, 2009.

[35] C. Peterhänsel and T. Lahaye, "Be fruitful and multiply: gene amplification inducing pathogen resistance," Trends in Plant Science, vol. 10, no. 6, pp. 257-260, 2005.

[36] M. Wolter, K. Hollricher, F. Salamini, and P. Schulze-Lefert, "The mlo resistance alleles to powdery mildew infection in barley trigger a developmentally controlled defence mimic phenotype," Molecular and General Genetics, vol. 239, no. 1-2, pp. 122-128, 1993.

[37] S. Lòpez-Fernàndez, S. Compant, U. Vrhovsek et al., "Grapevine colonization by endophytic bacteria shifts secondary metabolism and suggests activation of defense pathways," Plant and Soil, vol. 405, no. 1-2, pp. 155-175, 2016.

[38] M. van Hulten, M. Pelser, L. C. van Loon, C. M. J. Pieterse, and J. Ton, "Costs and benefits of priming for defense in Arabidopsis," Proceedings of the National Academy of Sciences of the United States of America, vol. 103, no. 14, pp. 5602-5607, 2006.

[39] R. Bari and J. D. G. Jones, "Role of plant hormones in plant defence responses," Plant Molecular Biology, vol. 69, no. 4, pp. 473-488, 2009.

[40] K. M. Pajerowska-Mukhtar, M. S. Mukhtar, N. Guex et al., "Natural variation of potato allene oxide synthase 2 causes differential levels of jasmonates and pathogen resistance in Arabidopsis," Planta, vol. 228, no. 2, pp. 293-306, 2008.

[41] M. Berrocal-Lobo and A. Molina, "Ethylene response factor 1 mediates Arabidopsis resistance to the soilborne fungus Fusarium oxysporum," Molecular Plant-Microbe Interactions, vol. 17, no. 7, pp. 763-770, 2004.

[42] P. J. Rushton, I. E. Somssich, P. Ringler, and Q. J. Shen, "WRKY transcription factors," Trends in Plant Science, vol. 15, no. 5, pp. 247-258, 2010.
[43] N. De Geyter, A. Gholami, S. Goormachtig, and A. Goossens, "Transcriptional machineries in jasmonate-elicited plant secondary metabolism," Trends in Plant Science, vol. 17, no. 6, pp. 349-359, 2012.

[44] S. Shin, J. Lv, G. Fazio, M. Mazzola, and Y. Zhu, "Transcriptional regulation of ethylene and jasmonate mediated defense response in apple (Malus $\times$ domestica) root during Pythium ultimum infection," Horticulture Research, vol. 1, article 53, 2014.

[45] S. Shin, P. Zheng, G. Fazio, M. Mazzola, D. Main, and Y. Zhu, "Transcriptome changes specifically associated with apple (Malus $x$ domestica) root defense response during Pythium ultimum infection," Physiological and Molecular Plant Pathology, vol. 94, pp. 16-26, 2016.

[46] B. C. Meyers, A. W. Dickerman, R. W. Michelmore, S. Sivaramakrishnan, B. W. Sobral, and N. D. Young, "Plant disease resistance genes encode members of an ancient and diverse protein family within the nucleotide-binding superfamily," Plant Journal, vol. 20, no. 3, pp. 317-332, 1999.

[47] J. L. Dangl and J. D. G. Jones, "Plant pathogens and integrated defence responses to infection," Nature, vol. 411, no. 6839, pp. 826-833, 2001.

[48] F. Jupe, L. Pritchard, G. J. Etherington et al., "Identification and localisation of the NB-LRR gene family within the potato genome," BMC Genomics, vol. 13, no. 1, article 75, 2012.

[49] R. Marathe, R. Anandalakshmi, Y. Liu, and S. P. Dinesh-Kumar, "The tobacco mosaic virus resistance gene, N," Molecular Plant Pathology, vol. 3, no. 3, pp. 167-172, 2002.

[50] X. Zhang, S. Shiu, A. Cal, and J. O. Borevitz, "Global analysis of genetic, epigenetic and transcriptional polymorphisms in Arabidopsis thaliana using whole genome tiling arrays," PLoS Genetics, vol. 4, no. 3, Article ID e1000032, 2008.

[51] C. M. Herrera and P. Bazaga, "Untangling individual variation in natural populations: ecological, genetic and epigenetic correlates of long-term inequality in herbivory," Molecular Ecology, vol. 20, no. 8, pp. 1675-1688, 2011.

[52] S. Feng and S. E. Jacobsen, "Epigenetic modifications in plants: an evolutionary perspective," Current Opinion in Plant Biology, vol. 14, no. 2, pp. 179-186, 2011.

[53] R. Velasco, A. Zharkikh, J. Affourtit et al., "The genome of the domesticated apple (Malus $\times$ domestica Borkh.)," Nature Genetics, vol. 42, no. 10, pp. 833-839, 2010. 

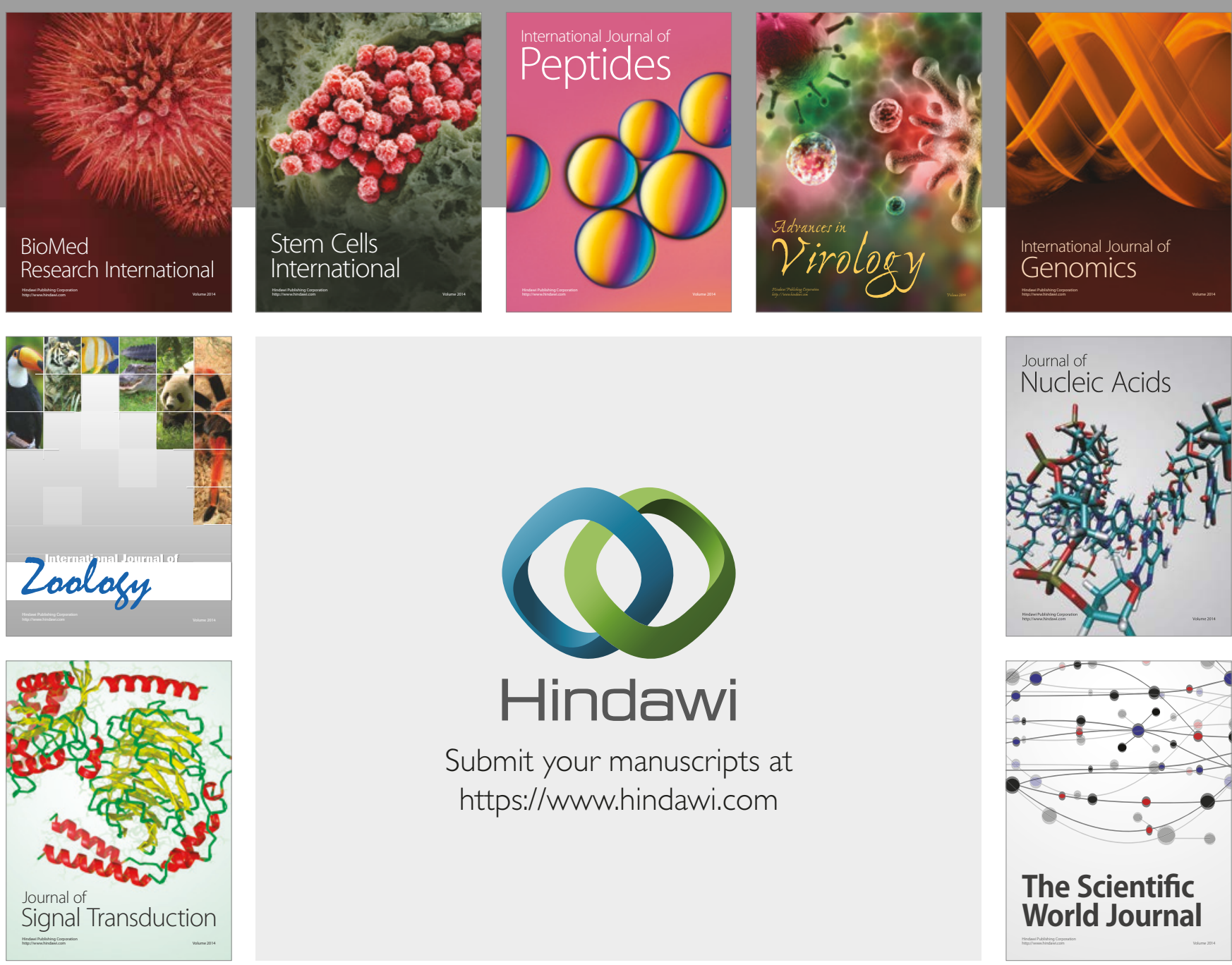

Submit your manuscripts at

https://www.hindawi.com
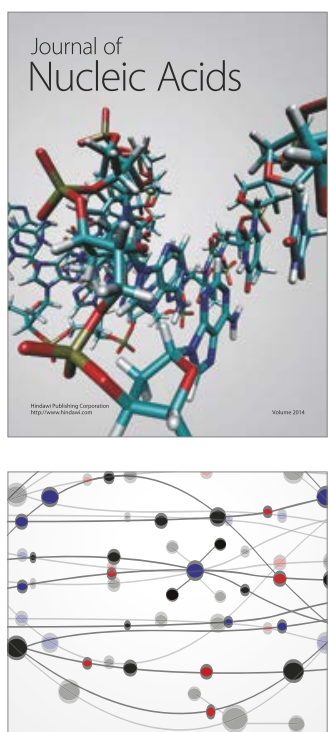

The Scientific World Journal

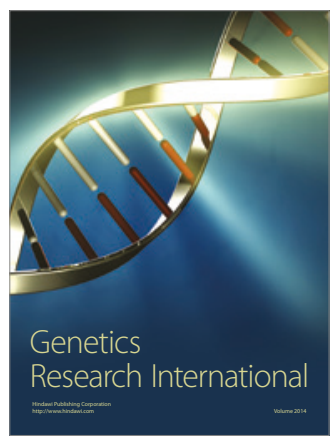

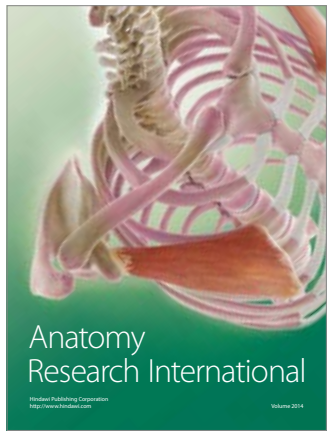

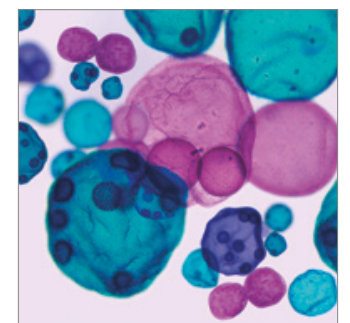

International Journal of Microbiology
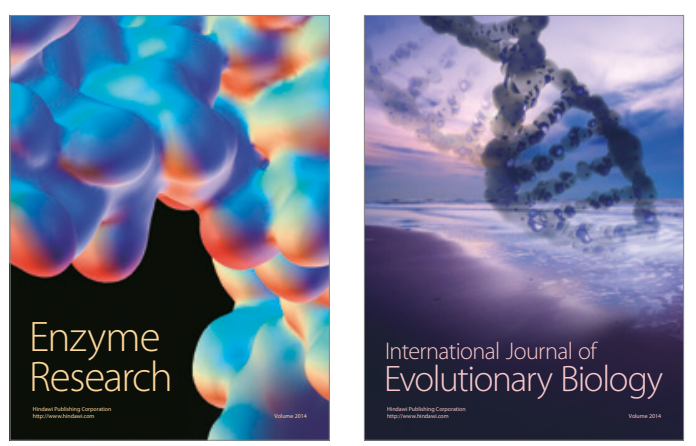
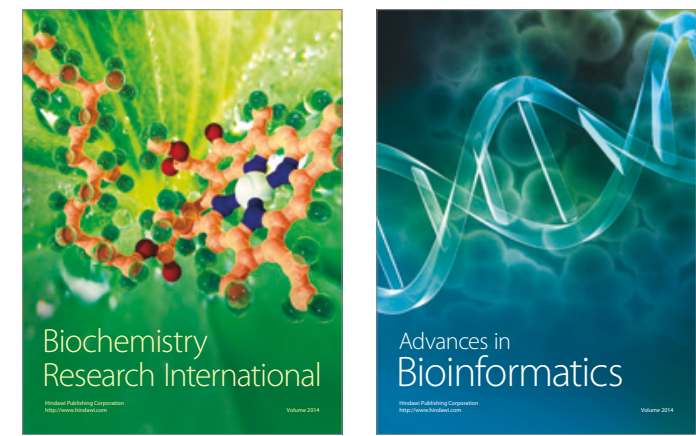

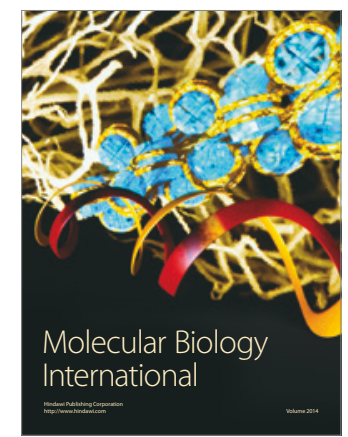

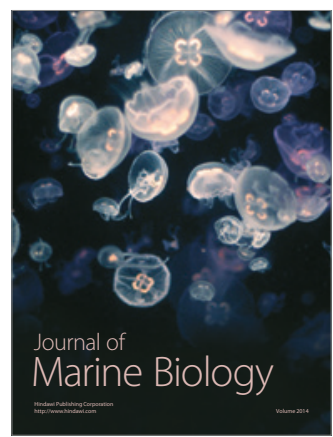

